\title{
THE USE OF PHYSICAL THERAPY FOR KNEE INJURIES IN CHILDREN
}

\section{M.A. Khan ${ }^{1,3}$, V.M. Krestyashin ${ }^{2,4}$, E.L. Vakhova ${ }^{1,3}$, I.V. Krestyashin ${ }^{2,4}$, O.Y. Zimina ${ }^{2,4}$}

\author{
${ }^{1}$ Moscow Scientific Practical Center of Medical Rehabilitation, Restorative \\ and Sports Medicine, Moscow, Russia \\ ${ }^{2}$ Russian Natoinal Reseaches Medical Univercity of N.I. Pirogov, Moscow, \\ ${ }^{3}$ I.M. Sechenov First Moscow State Medical University, Moscow, Russia \\ ${ }^{4}$ Children State Clinical Hospital №13 of N.F. Filatov
}

Various injuries of the knee account for 5 to $25 \%$ of all injuries of the musculoskeletal system in children and are among the most expensive injuries, which often require surgery and intensive rehabilitation $[1,2]$. Currently, physical factors are widely used in the medical rehabilitation of children with the knee injury, including after arthroscopic operations in the early rehabilitation period [3-5].

However, evidence-based recommendations for medical rehabilitation of children with post-traumatic non-specific pain in the knee joint in children in the absence of intra-articular lesions seem not effective enough due to changes in functional status of a limb in regard to musculoskeletal system as a whole.

Clinical observations and comparative studies of the effectiveness of the integrated application of pulsed low-frequency electrostatic field and physical therapy exercises were performed in 40 children with posttraumatic stress pain syndrome aged $6-18$ years.

Complex application of pulsed low-frequency electrostatic field and physical therapy helped to improve the general state of the middle of the course. These sensory-analogue scale showed a significant decrease of the intensity of pain by the end of treatment (from $4.27 \pm 0.05$ to $1,12 \pm 0,13$ points, $\mathrm{p}<0.05$.).

Under the influence of combined use of pulsed low frequency electrostatic field and physiotherapy mentioned tone and muscle strength recovery, eliminating the stiffness of the knee joint, reducing the severity of muscle wasting femur as hip circumference reduction volume deficit of 1.7 .

Results of dynamic knee ultrasound recorded leveling inflammatory changes, signs of synovitis knee joints under the influence of combined use of pulsed low frequency electrostatic field and physical therapy. The dynamics of average scoring echographic changes in the joint ranged from $3.8 \pm 0.71$ to $0.3 \pm 0.21$ score, $p<0.05$.

Investigation of capillary blood flow by laser Doppler flowmetry enabled to establish a favorable
Article history:

Received 10 April 2019

Received in revised form 15 April 2019

Accepted 19 April 2019 level of tissue perfusion dynamics in children in a normalizing microcirculation indicator as in congestive stagnant-type microcirculation: from $18.6 \pm 1.14$ to $13.6 \pm 0.74$ pf.unit., and in the spastic type: from $5.6 \pm 0.56$ to $8.4 \pm 1.12$ pf.unit. The frequency registration microcirculation type increased by 3.3 times while reducing the frequency of adverse registration types microcirculation: hyperemic-stagnant 2.5 times, spastic -2 times.

These infrared thermography showed significant decreasein thermoasymmetry periarticular damaged tissue joints and symmetrical with $1.8 \pm 0.04^{\circ} \mathrm{C}$ to $0.3^{\circ} \mathrm{C} \pm 0.02(\mathrm{p}<0.05)$ after a course of action of physical factors that correlate with by laser Doppler flowmetry.

Comprehensive assessment of therapeutic efficacy on combined use of pulsed low frequency electrostatic field and physical therapy in children with post-traumatic pain syndrome was $95.0 \%$

Thus, a new technology for medical rehabilitation has been developed and scientifically substantiated on children with post-traumatic pain syndrome. Its use was positively confirmed against a background of $d y-$ namic control over post-traumatic inflammation with the help of non-invasive diagnostic techniques.

\section{REFERENCES}

1. Avramenko V.V., Kuznetsov I.A. An arthroscopy at internal damages of a knee joint in children and teenagers//Traumatology and orthopedics of Russia. 2011. - 4 (62). - Page 131-139.

2. Merkulov V.N., ERemushkin M.A., Yeltsin A.G., DovluR R.K. Rehabilitation of children and teenagers with injuries of a front crucial ligament of a knee joint//the Messenger of recovery medicine. 2015. - No. 3. - Page 7-12.

3. Khan M. A., Konova O.M., Vybornov D. Yu. Air local cryotherapy at traumatic damages in children.//A grant programme for doctors. - M, 2003. $-9 \mathrm{p}$.

4. Prokhorova E.V., Vybornov D. Yu. Post-traumatic arthritises of knee joints in children. Bases of complex pathogenetic treatment.//Russian messenger of children's surgery, anesthesiology and resuscitation. 2011. - No. 2. - Page 108-111.

5. Physical and rehabilitation medicine. National leaders.//Under G.N. Ponomarenko's edition. M.: "GEOTAR-media". 2016. - 685 p. 